\title{
INTERROGANDO A LA SOBERANÍA ALIMENTARIA. UNA RESEÑA DEL LIBRO REGIMMENES ALIMENTARIOS Y CUESTIONES AGRARIAS DE PHILIP MCMICHAEL, 2015
}

\author{
Darcy Tetreault*
}

Regimenes alimentarios y cuestiones agrarias de McMichael es el tercer libro de la serie "Iniciativa para Estudios Agrarios Críticos" (ICAS, por sus siglas en inglés) que pretende producir "pequeños libros sobre el estado del arte de grandes cuestiones» (p. 5). De acuerdo con este propósito, McMichael propone que su libro sea «un intento de reescribir el proyecto de régimen alimentario, no tanto de un modo exhaustivo, sino más bien ilustrativo, para plantear nuevas preguntas relacionadas con el mundo de lo agroalimentario en general y con el enfoque de régimen alimentario en particular» ( $p$. 8). Desde mi punto de vista, cumple cabalmente con este propósito. Representa una síntesis de más de 30 años de trabajo en el desarrollo de dicho enfoque, en colaboración con Harriet Friedmann y otros investigadores. $\mathrm{Al}$ mismo tiempo, el libro es mucho más que una síntesis coherente y actualizada de los trabajos anteriores del autor, ya que contribuye a ampliar y complejizar el enfoque de régimen alimentario, rearticulándolo con el concepto y la agenda política de la soberanía alimentaria. De esta manera, McMichael fortalece la postura «campesinista» en los debates en torno a la cuestión agraria y señala cómo los campesinos organizados en el movimiento internacional Vía Campesina ofrecen una alternativa al régimen alimentario corporativo y una salida a la crisis multidimensional que padece el campo en todas partes del mundo.

\footnotetext{
* Docente-investigador del Doctorado en Estudios del Desarrollo de la Universidad Autónoma de Zacatecas, México.
} 
Empecemos con un breve resumen del contenido del libro, su esquema capitular y los principales argumentos avanzados, para posteriormente presentar una serie de críticas, dudas y preguntas.

\section{RESUMEN CAPITULAR Y DESTILACIÓN DE ARGUMENTOS}

El libro Regímenes alimentarios y cuestiones agrarias se compone de siete capítulos. El primero, titulado «El proyecto de régimen alimentario», reconstruye la historia de este enfoque, apuntando hacia los trabajos seminales de Friedmann y del propio McMichael en los años ochenta. La emergencia de este enfoque durante los años ochenta no es una casualidad, más bien «fue un producto de su tiempo» (p. 13), según McMichael, debido a que nació durante una fase de transición de un régimen alimentario a otro.

Según McMichael, el proyecto de régimen alimentario surgió «para especificar las relaciones entre el ordenamiento del mundo y el comercio agroalimentario. Afirmaba que los episodios de reestructuración y transición están delimitados por periodos de patrones estables de acumulación». Como tal, «se trata de un enfoque intrínsecamente comparativo de la historia mundial reciente» (p. 15). En efecto, es un enfoque que pide prestados elementos del enfoque del sistema mundo de Wallerstein y de la regulación de la acumulación de capital, particularmente en la formulación de Aglietta.

En el primer capítulo, McMichael esboza los tres regímenes alimentarios que han operado sucesivamente a nivel mundial desde finales del siglo XIX: 1) el régimen centrado en Inglaterra entre 1870 y 1930; 2) el régimen centrado en Estados Unidos entre 1950 y 1970, y 3 ) el régimen alimentario corporativo, centrado en el poder corporativo financiero, desde 1980 hasta el presente. Citando a nuestro autor: «La configuración del poder en cada periodo ha sido muy distinta, siendo el elemento unificador, la organización de la producción y circulación mundial de alimentos para sostener aquella configuración de poder enraizada en una dinámica de acumulación particular» (p. 24). 
El segundo capítulo analiza con mayor detalle los primeros dos regímenes, además de presentar una «prehistoria» al describir los antecedentes en el periodo colonial de los siglos XVII y XVIII, que convirtió partes del mundo no europeo en proveedores de «artículos de placer», es decir, estimulantes como el tabaco, café, té y azúcar. McMichael considera que estos antecedentes no constituyen la formación de un régimen alimentario, debido a que no resultaron en el surgimiento de un precio mundial para los alimentos básicos, algo que sucedió hasta el último cuarto del siglo xix (p.43). Sobre este punto se puede observar cómo el enfoque de régimen alimentario privilegia la esfera de circulación del capital.

El primer régimen, centrado en Gran Bretaña a finales del siglo xix, combinó la importación de granos básicos y ganado de las ex colonias tipo settler (por ejemplo, Estados Unidos, Canadá, Australia), con la importación de productos tropicales de las colonias del Sur, reduciendo así el costo de la alimentación para la fuerza de trabajo en Europa, lo que a su vez facilitaba la acumulación del capital industrial, especialmente en Inglaterra, que pretendía ser el «taller del mundo». Según nos explica el autor, el hilo conductor de este régimen se traza por la emergencia de un mercado mundial para el trigo (p. 23).

El segundo régimen alimentario, de acuerdo con el esquema de Friedmann y McMichael, emergió después de la Segunda Guerra Mundial, bajo la hegemonía de Estados Unidos, en el contexto de la Guerra Fría. Durante este periodo Estados Unidos utilizó la ayuda alimentaria como un arma política para ganar la lealtad de los países recién independizados, ante la amenaza que representaba la alternativa de alinearse con el bloque soviético. De esta manera, Estados Unidos aseguraba colocar su excedente agrícola en los mercados de los países incluidos en su imperio informal, especialmente los granos básicos, producidos con subsidios y tecnología de punta. El dumping fomentaba la dependencia alimentaria al mismo tiempo que subsidiaba la acumulación de capital en el emergente sector manufacturero de algunos países del Sur. Por otra parte, como señala McMichael, el desarrollo y la diseminación de las tecnologías de la «revolución verde» ayudó a consolidar la emergencia de una clase 
de grandes agricultores capitalistas en el Sur; mientras que en el terreno ideológico ayudó a consolidar la supremacía del enfoque productivista agroindustrial.

El capítulo tres del libro se dedica a explorar los contornos del régimen alimentario corporativo que emergió a partir de los años ochenta, en el contexto de la crisis de la deuda, cuando Washington impuso los ajustes estructurales neoliberales en los países del Sur, con el apoyo de las facciones dominantes de la gran burguesía de los mismos países. McMichael señala que existe cierto debate sobre si ha habido o no un tercer régimen alimentario y pregunta si es suficiente el binario estándar Estado-mercado, asociado con los dos primeros regímenes, para capturar la complejidad del actual periodo. Evidentemente, su postura es que sí existe un nuevo régimen, a pesar de la aparente inestabilidad del mismo.

El régimen corporativo se caracteriza por la hegemonía de las compañías agroalimentarias transnacionales y del capital financiero, la internacionalización de la agricultura, la financiarización de los mercados mundiales y la concomitante especulación sobre los precios agrícolas. Además, se caracteriza por el acaparamiento de tierras agrícolas y otros recursos naturales, la centralidad de los «cultivos flexibles» (principalmente soya, maíz, caña de azúcar y aceite de palma, que son posibles de intercambiar para fines alimenticios o para producir agrocombustibles) y la proliferación de supermercados multinacionales.

McMichael explora la gobernanza de este régimen bajo los auspicios de la Organización Mundial de Comercio (омс), así como las sucesivas rondas de negociación que han dejado intactos los grandes subsidios dirigidos al sector agrícola en Estados Unidos y la Unión Europea, mismos que se capturan en mayor medida por las compañías transnacionales. Además, al final del capítulo, introduce el concepto de soberanía alimentaria como una alternativa al régimen corporativo.

En el capítulo cuatro, McMichael aborda la cuestión agraria desde el enfoque de régimen alimentario. Observa que en el planteamiento clásico de la cuestión agraria a principios del siglo $\mathrm{xx}$, «la preocupación 
inmediata fue la cuestión de en qué medida y si las relaciones capitalis tas estaban erosionando la propiedad precapitalista de la tierra rural, y cómo esto podría contribuir a una alianza obrero urbano-rural» (p. 95). Como tal, «no contemplaba la ecología de la tierra, y tampoco toma en cuenta a los agricultores-campesinos como sujetos históricos» (p. 95).

En efecto, Lenin argumentaba que el campesinado tenía el destino de desaparecer conforme la penetración de relaciones mercantilistas impulsaba un proceso de diferenciación entre el campesinado, con una progresiva polarización entre la burguesía rural y los explotados del campo, o sea, el proletariado agrícola, el semiproletariado y los pequeños campesinos. En este esquema, el líder de los bolcheviques veía al proletariado agrícola como un aliado potencial para las luchas protagonizadas por la clase obrera.

Kautsky, por su parte, argumentaba que los pequeños productores del campo no necesariamente iban a desaparecer, debido a que ciertas políticas públicas pueden favorecer su explotación indirecta a través del intercambio $y$, relacionado con esto, porque los campesinos tienen la capacidad de sobreexplotarse a sí mismos. Como señala McMichael, en éstas y otras formulaciones «clásicas» de la cuestión agraria, los campesinos no se perfilan como agentes con potencial revolucionario.

El enfoque clásico de la cuestión agraria estudiaba la transformación del campo en los Estados nacionales de Europa sin prestar suficiente atención, según McMichael, a las relaciones internacionales que históricamente acondicionan tales transformaciones. Si bien Kautsky reconocía que los orígenes de la crisis agraria en Europa a finales del siglo XIX se ubicaban en las relaciones internacionales que habían traído consigo la importación masiva de granos básicos baratos, lo cierto es que su formulación de la cuestión giraba en torno a la problemática de acumulación. De esta manera, privilegiaba la teoría del capital sobre la historia (p. 105). Como señala McMichael, «la consecuencia del enfoque de las relaciones de la producción es de deshistorizar las condiciones agrarias» (p. 116). Ante esta tendencia, plantea la necesidad de reformular la cuestión agraria a nivel mundial, centrarla en la dinámica del 
régimen alimentario en situaciones históricas concretas -incluso en la periferia de la economía mundial - y tomar en cuenta factores ecológicos. Además, sugiere emplear la lente de la soberanía alimentaria para considerar al movimiento contrahegemónico Vía Campesina. En sus palabras, «se necesita la voz de un campesin[ado] movilizado y un movimiento obrero sin tierra para articular una cuestión agraria más compleja con respecto a la crisis contemporánea del capitalismo, y plantear así una ruta ontológica alternativa» (p. 123).

El capítulo 5 pretende ampliar ciertas dimensiones del enfoque de régimen alimentario al emplearlo «para identificar relaciones significativas y contradicciones en la historia política del capital a través del espacio y el tiempo» (p. 125). Esto se hace, primero, con un análisis del régimen alimentario en tres grandes regiones: Asia Oriental, América Latina y el Medio Oriente. Luego, se exploran las relaciones del régimen alimentario en cuatro dimensiones: 1) los rostros sociales de género, raza y trabajo; 2) la financiarización, considerada como una de las relaciones estructurantes clave del régimen corporativo, ya que ha conducido a «una integración cada vez mayor y una recomposición de la cadena agroalimentaria a través del espacio y el tiempo» (p. 147); 3 ) la nutricionalización, que se deriva de «la transición de las dietas basadas en vegetales, hacia el consumo de proteínas animales, aceites y grasas, azúcares procesadas y carbohidratos procesados» (p. 151), y 4) la ecología, donde se retoma el concepto de «ruptura metabólica» de Marx para analizar las consecuencias ecológicas de subordinar la agricultura al capital, industrializar la producción de comida y transportarla a grandes distancias.

En el capítulo 6, titulado «Crisis y reestructuración», McMichael explica la crisis alimentaria con base en un análisis complejo que combina factores político-económicos y ecológicos de largo plazo con otros coyunturales, ubicando así la crisis alimentaria de 2007 y 2008 en una crisis multidimensional del capitalismo desde principios de los años setenta. Mientras Harvey (2003) explica esta crisis generalizada en términos de «sobreacumulación de capital», McMichael lo hace con un enfoque en la subreproducción (under reproduction) del trabajo y las 
ecologías que en última instancia sostienen la economía mundial y la vida misma. La siguiente cita articula de manera sucinta los factores que McMichael considera clave para explicar la crisis alimentaria:

la reciente inflación de los precios de alimentos es un evento, en la coyuntura política del neoliberalismo, dentro de la longue durée (largo plazo) del capitalismo. Es decir, la llamada «crisis alimentaria mundial» constituye una estratificación de las relaciones espacio-temporales, en particular, el ciclo de más largo plazo de agroindustrialización, que implica su simplificación a través del monocultivo y la creciente dependencia de los combustibles fósiles, junto con descensos coyunturales en los rendimientos de producción de alimentos y los efectos generados por la inflación entre las compensaciones de los agrocombustibles y la especulación financiera. El aumento de los costos, relacionado con los sustitutos en el auge del petróleo y de los cultivos para agrocombustibles, se combinan con los precios monopólicos de la agroindustria para elevar los precios de los alimentos a nivel mundial, transmitidos globalmente a través de maneras liberalizadas de las finanzas, el comercio y la seguridad alimentaria (p. 160).

Después de explicar la crisis en estos términos, el sexto capítulo del libro explora otros temas relacionados con la crisis alimentaria, incluyendo la «bioeconomía», el «mercantilismo de la agroseguridad» y el acaparamiento de tierras, agua y espacios de conservación natural.

El séptimo y último capítulo del libro aquí reseñado abre la pregunta del valor, en relación con los regímenes alimentarios, como un eje de análisis comparativo entre el fetichismo de las relaciones de valor de cambio en el capitalismo versus los valores de uso de los campesinos en la vanguardia de los movimientos en torno a la soberanía alimentaria y la agroecología. El capítulo avanza sobre dos piernas: la primera explora las perversas consecuencias sociales y ecológicas del régimen alimentario corporativo; la segunda encuentra sustento en los discursos, prácticas y visiones normativas de los campesinos vanguardistas en todas partes del mundo.

Como bien nos explica McMichael, el régimen corporativo concentra el poder y la riqueza en las grandes corporaciones transnacionales 
que controlan las cadenas agroalimentarias de producción y comercialización en el ámbito global. Estas corporaciones desarrollan tecnologías agroindustriales que externalizan los costos ecológicos y sociales. De esta manera, el régimen corporativo conduce a diversas formas de degradación ambiental, incluyendo la erosión de la biodiversidad y el calentamiento global, además de impulsar una tendencia alimenticia a nivel mundial que paradójicamente combina crecientes niveles de obesidad con la persistencia de hambre y desnutrición entre grandes sectores de la población.

McMichael propone reformular la cuestión agraria como una cuestión de alimentación, «reconociendo que como uso de valor, los alimentos tienen cualidades metabólicas, que vinculan a los humanos con el medio ambiente» (p. 195). Desde esta perspectiva, el régimen alimentario corporativo sólo valora la producción agrícola en términos de su valor de cambio como mercancía, borrando su valor de uso, sobre todo en el caso de los cultivos «flexibles» que pueden valorizarse no sólo en las cadenas agroalimentarias, sino también en la producción de biocombustibles ( $\mathrm{p}$. 191). En cambio, las «culturas de maíz» asignan un valor simbólico al maíz (p. 189) y las tecnologías locales con bajos insumos externos, tales como las que se emplean en las tradicionales milpas con policultivos, ayudan a conservar la biodiversidad y también la diversidad cultural (p. 200).

McMichael apunta hacia la multifuncionalidad de la agricultura sustentable y observa que la visión de los líderes del Movimiento de los Trabajadores sin Tierra en Brasil no basa su discurso y práctica en «un concepto abstracto de [...] valor, sino que más bien prefigura una ontología política que valora directamente la práctica de auto-organización a través de redes de cooperación» (p. 200). En este caso, el movimiento impulsa un proceso de recampesinización que, argumenta McMichael, contribuye a la reparación de la ruptura metabólica, en la medida en que los habitantes de barrios pobres se mudan al campo para adoptar prácticas agroecológicas.

Sobre la recampesinización, McMichael cita el trabajo de Van der Ploeg - el autor del segundo libro de la serie de ICAS - para sostener el argumento de que la recampesinización es una tendencia que se puede 
observar también en Europa, donde el campesino moderno entra en «coproducción con una naturaleza viva», con base en «recursos de dominio propio y autogestionados» para agregar valor, además de complementar sus ingresos con la participación en la pluriactividad no agraria (p. 208). McMichael vincula el concepto de «capital ecológico» manejado por Van der Ploeg con el concepto de soberanía alimentaria para argumentar a favor de las alternativas propuestas por Vía Campesina, las cuales proyectan una visión de pequeños productores que practican la agroecología para alimentar al mundo. Para señalar el potencial de estas alternativas, hace referencia a varios estudios que concluyen que los rendimientos de la producción agroecológica son suficientes para alimentar al mundo. Además, McMichael apunta hacia la experiencia cubana, donde el movimiento agroecológico en el campo y la agricultura orgánica urbana han impulsado un aumento impresionante en la producción de frutas, verduras, maíz, frijoles, plantas medicinales y carne de puerco, mejorando así las dietas de las y los cubanos y fortaleciendo la soberanía alimentaria en los ámbitos local y nacional (p. 216).

En el penúltimo apartado de la conclusión, McMichael revisa los logros del movimiento Vía Campesina. Lo que se puede destilar aquí es que los logros de la Organización de las Naciones Unidas (onU) y demás instituciones de gobernanza global se limitan en gran medida al campo de batalla ideológica, donde «se ha producido un desplazamiento en el equilibrio de fuerzas morales en relación a que las instituciones neoliberales han sido comprometidas» (p. 220). Por otra parte, McMichael señala que al menos dos docenas de países han adoptado el derecho a la alimentación y seis han incorporado el concepto de soberanía alimentaria en el orden constitucional, incluyendo tres de Sudamérica: Bolivia, Ecuador y Venezuela. Su análisis de estas experiencias es necesariamente somero y no toma en cuenta, por ejemplo, los hallazgos de una investigación reciente de McKay et al. (2014, un año después de la publicación en inglés de Regímenes alimentarios y cuestiones agrarias) que concluye que sólo en Venezuela se pueden observar políticas públicas y cambios institucionales que promueven el control local sobre la alimentación, 
mientras que en Bolivia y Ecuador la soberanía alimentaria se queda en mayor medida en el nivel retórico.

Para concluir, McMichael yuxtapone una vez más el modelo de agroindustrialización, que produce alimentos y agrocombustibles «sin lugar de origen», y las formas de agricultura agroecológica enraizadas en el ámbito local y nutridas por las políticas de soberanía alimentaria. No deja ninguna duda sobre a su entusiasmo para la soberanía alimentaria, que para él constituye «[una] ontología política formativa, construyendo valores contrarios a la autovalorización antiética del capital a cualquier costo» (p. 223). Así, a fin de cuentas, se trata de valores.

\section{CRÍTICAS, DUDAS Y PREGUNTAS}

Mi primera duda es: ¿por qué no se menciona a Chayanov? Mientras que Van der Ploeg se autodeclara chayanoviano en el título de su libro de la serie de ICAs, McMichael ni siquiera menciona su nombre. En todo caso, se puede observar que el concepto y la agenda de soberanía alimentaria, tal como se formulan por McMichael en este libro, descansan en gran medida sobre la idea chayanoviana de que los campesinos aplican —o pueden aplicaruna lógica alternativa en sus actividades productivas; ${ }^{1}$ una lógica que no busca la acumulación de capital, sino satisfacer las necesidades básicas de la reproducción familiar y social. Se trata de valores alternativos. En la formulación de McMichael, el movimiento campesino en torno a la soberanía alimentaria está en el proceso de rescatar y desarrollar estos valores, contrarios a los que predominan en el capitalismo, al tomar en cuenta no sólo cálculos económicos (la maximización de los ingresos monetarios), sino también el medio ambiente y consideraciones culturales. En este sentido, la epistemología de McMichael es «chayanoviana», aunque el proyecto de regímenes alimentarios no lo es.

\footnotetext{
${ }^{1}$ Esto se hace explícito en la siguiente cita: «los campesinos bajo la presión de la agricultura industrial no internalizan necesariamente las relaciones mercantiles en las prácticas del hogar/medios de vida» (p. 116).
} 
En términos más generales, el enfoque de McMichael puede ser clasificado como «campesinista», para utilizar el término popularizado en los grandes debates que tuvieron lugar en México durante los años setenta y ochenta, entre los «campesinistas» (por ejemplo, Armando Bartra y Gustavo Esteva) y los «descampesinistas»o «proletaristas» (por ejemplo, Roger Bartra y Luisa Paré). Hay diferentes variantes de cada acercamiento (Otero, 2004); no voy a detallarlos aquí. En términos básicos e incluso simplistas, los descampesinistas argumentan que la inexorable expansión del capitalismo en el campo conlleva a un proceso no siempre lineal pero constante en dirección a la proletarización y semiproletarización de los campesinos. Desde esta perspectiva, los campesinos tienen poco potencial revolucionario o, aún peor, ya no existen. Este es el argumento desarrollado por Henry Bernstein - autor del primer libro de esta serie-, quien argumenta que «no se gana nada, y se oculta mucho, al caracterizar a los pequeños agricultores contemporáneos como "campesinos" » (2006:454).²

En cambio, los campesinistas constan que los campesinos todavía existen, no han desaparecido como predecía el marxismo ortodoxo y también la teoría de modernización. Además, desde esta perspectiva, los movimientos campesinos tienen una orientación anticapitalista y constituyen una agencia revolucionaria; son los movimientos más dinámicos y poderosos de la actualidad. Ésta es evidentemente la postura de McMichael. La comparto, pero pregunto: ¿quiénes son los campesinos? McMichael no ofrece una definición, ni siquiera en el glosario que se encuentra a final del libro. Por consecuencia, el libro exhibe cierta ambigüedad con respecto a la identificación de los sujetos sociales (agencia) de los movimientos campesinos contemporáneos. En varios lugares del libro, se refiere a estos sujetos como «los pequeños agricultores,

${ }^{2}$ Bernstein (2012) argumenta que no hay «campesinos» en el mundo contemporáneo de la globalización capitalista, basando su argumento en los siguientes factores: «la mercantilización de la subsistencia», la transformación de los campesinos en la dirección de producción mercantil simple, la resultante internalización de las relaciones mercantiles en la reproducción de las familias que practican la agricultura, y las tendencias de diferenciación inherente en la producción mercantil simple, sin importar si la agricultura se practica o no como el único o principal sustento de la reproducción social, o si se combina con otras actividades. 
pastores y pescadores», los «que permanecen en el campo [... $]$ con y $\sin$ tierra» $y$ «la gente de la tierra». Estas generalizaciones ocultan la diferenciación de clases sociales en el campo y, por tanto, sacrifican cierta medida de rigor analítico. Por otra parte, la misma ambigüedad puede tener una función política, en tanto invita a una amplia gama de «actores» a unirse a la lucha a favor de la soberanía alimentaria. En efecto, McMichael reconoce esta función política cuando cita a Paul Nicholson, miembro fundador de Vía Campesina, quien dice que «El debate no está centrado en la palabra "agricultor" o "campesino". El debate trata más sobre un proceso de cohesión» (p. 215). Desde este punto de vista, el concepto de «campesino» no se refiere tanto a una condición de clase (su relación con los medios de producción), sino más bien a la identidad política, construida de manera colectiva para impulsar la agenda de soberanía alimentaria.

Apoyo a Vía Campesina, incluso con respecto a la promoción de la agroecología, pero tengo ciertas dudas sobre la posibilidad de generalizar las prácticas agroecológicas en los intersticios del sistema capitalista, y también sobre el potencial de la agroecología de pequeña escala para producir suficientes cantidades de granos básicos para «alimentar al mundo». Me explico.

La agricultura orgánica y de pocos insumos externos implica más mano de obra. El trabajo del campo es duro y bajo las condiciones estructurales del capitalismo neoliberal, el esfuerzo físico adicional se recompensa muy poco en términos monetarios. Como me explicó un agricultor nahua de la Sierra de Manantlán en el centro occidente de México, donde se produce maíz principalmente para el autoconsumo en pequeñas parcelas sobre las laderas de las montañas: «un litro de herbicida es barato, con ello puedes rociar una milpa de dos hectáreas en un solo día, en vez de dedicarle 10 días de trabajo con cazanga».3 Además, en México, es difícil vender frutas y verduras a un precio «justo», por encima del promedio, para reflejar la sustentabilidad ecológica y social.

\footnotetext{
${ }^{3}$ Para una descripción de las prácticas agropecuarias en la Sierra de Manantlán, específicamente en el ejido de Ayotitlán, y también sobre las prácticas en el ejido La Ciénega, mencionado más adelante, véase Tetreault (2009).
} 
Por tanto, hay relativamente pocos agricultores en la Sierra de Manantlán que han abrazado los principios y tecnologías de la agroecología.

Podemos observar algo parecido en La Ciénega, un ejido ubicado en el occidente del estado de Jalisco, cerca de El Grullo y Autlán, en un valle con tierras planas, fértiles e irrigadas. Allí, sólo tres de los 140 ejidatarios han abrazado la agroecología; los demás rentan sus parcelas a compañías productoras de agave, o bien practican formas convencionales de agricultura. No están dispuestos a hacer el trabajo físico que implica la agroecología. En efecto, para hacerlo, se requiere una constelación de valores alternativos, algo que se refleja en los discursos de los agricultores de La Ciénega que sí practican la agroecología, por ejemplo, al reconocer los beneficios del trabajo físico para la salud, sobre todo en parcelas libres de agroquímicos, además de valorar la autonomía, la provisión de comida sana para sus familias y el medio ambiente.

¿Cómo se pueden generalizar las prácticas agroecológicas y cuáles son sus límites? Propongo que la experiencia de Cuba es instructiva al respecto. Como se señala en el libro de McMichael, después del colapso de la Unión Soviética, Cuba tenía que reorientar su producción agropecuaria hacia las necesidades alimenticias de su población, con poco acceso al petróleo y otros insumos agroindustriales. La necesidad urgente se manifestó y el giro hacia la agroecología resultó en incrementos impresionantes en la producción de varios cultivos, sobre todo frutas y verduras. En este caso, un movimiento popular desde abajo logró abrir y ampliar una apertura en el Estado (Rosset et al., 2011) para la creación de políticas públicas orientadas a dar impulso a la ampliación de prácticas agroecológicas y agricultura urbana en todas partes de la isla (Koont, 2011). Esto es un factor importante; apunta hacia el papel clave que puede jugar o no el Estado en promover la agroecología. Otro factor importante son los incentivos económicos. Los trabajadores en los organopónicos urbanos de Cuba ganan muy bien en términos relativos, más de tres veces el salario promedio en el sector público.

Por último, mi duda sobre las posibilidades de producir suficientes cantidades de granos básicos en granjas pequeñas que utilizan pocos 
insumos externos, con técnicas orgánicas. Retomando el ejemplo de Cuba, que probablemente es el caso de éxito más espectacular de la agroecología a nivel nacional, se puede observar que, mientras los incrementos en la producción de frutas, verduras y otros cultivos han sido dramáticos desde los años noventa, la isla todavía exhibe altos niveles de dependencia alimentaria en el área de los granos básicos. ¿La agroecología de escala pequeña se presta a producir grandes cantidades de cereales, suficientes para alimentar el mundo? ¿Cuáles serían las implicaciones en cuanto a la fuerza de trabajo requerida y su impacto en los precios de alimentación?

Estas preguntas y críticas se desprenden de un trabajo magistral de exploración teórica y empírica. Pretenden ser provocativas. El libro de McMichael aporta elementos novedosos a los debates contemporáneos en torno a la cuestión agraria, herramientas poderosas para entender la crisis del campo desde una perspectiva histórica de largo plazo y argumentos sólidos para apostar por y apoyar a los movimientos campesinos que luchan bajo la bandera de soberanía alimentaria.

\section{BIBLIOGRAFÍA}

Bernstein, Henry (2006), «Is There an Agrarian Question in the 21st Century?», Canadian Journal of Development Studies, vol. 27, núm. 4, pp. 449-460.

_ (2012), Dinámicas de clase y transformación agraria, México, Miguel Ángel Porrúa, UAZ.

Harvey, Darcy (2003), The New Imperialism, Oxford, Oxford University Press.

Koont, Sinan (2011), Sustainable Urban Agriculture in Cuba, Gainesville, University Press of Florida.

McKay, Ben, Ryan Nehring y Marygold Walsh-Dilley (2014), «The 'State' of Food Sovereignty in Latin America: Political Projects and Alternative Pathways in Venezuela, Ecuador and Bolivia», The Journal of Peasant Studies, vol. 41, núm. 6, pp. 1175-1200.

McMichael, Philip (2015), «Regímenes alimentarios y cuestiones agrarias», México, Miguel Ángel Porrúa, uaz. 
Отево, Gerardo (2004), ¿Adiós al campesinado? Democracia y formación política de las clases en el México rural, México, Miguel Ángel Porrúa, uaz, Simon Fraser University.

Rosset, Peter et al. (2011), «The Campesino-to-Campesino Agroecology Movement of AnAP in Cuba: Social Process Methodology in the Construction of Sustainable Peasant Agriculture and Food Sovereignty», Journal of Peasant Studies, vol. 38, núm. 1, pp. 161-191.

Tetreault, Darcy (2009), Pobreza y degradación ambiental. Las luchas de abajo en dos comunidades del occidente de Jalisco: Ayotitlán y La Ciénega, Guadalajara, Universidad de Guadalajara.

Van der Ploeg, Jan Douwe (2015), El campesinado y el arte de la agricultura. Un manifiesto chayanoviano, México, Miguel Ángel Porrúa, uAz. 
